\title{
Saberes matemáticos e história de vida na zona rural de Marabá-PA
}

\author{
Carlos Gaia ${ }^{1}$, Lucas Silva Pires ${ }^{2}$ \\ ${ }^{1}$ Universidade Federal do Sul e Sudeste do Pará - UNIFESSPA, Faculdade de Educação do Campo/Instituto de \\ Ciências da Educação - FECAMPO/ICH. Folha 31, Quadra 07, Lote Especial; Marabá-PA. Brasil. \\ carlosgaia04@ hotmail.com. ${ }^{2}$ Universidade Federal do Sul e Sudeste do Pará - UNIFESSPA.
}

RESUMO. O artigo apresenta resultados parciais de uma pesquisa socioeducacional de Estágio Docência II, com ênfase em Matemática, realizada na Comunidade Flor do Ipê. O objetivo consiste em refletir e apresentar Práticas com Matemáticas a partir de narrativas de sujeitos do campo. Tem como base de dados às histórias de vida e trabalho da atividade pecuária de produtores de leites da referida comunidade. Os resultados indicam que a valorização de saberes matemáticos oriundos das práticas sociais do campo contribui para a o fortalecimento de alguns princípios políticos, pedagógicos e didáticos do ensino escolar do campo. Além da formação contextualizada, a realidade e as experiências das comunidades do campo como objeto de estudo e fonte de conhecimento.

Palavras-chave: Educação do campo, Narrativas, Práticas com matemáticas. 


\title{
Mathematical knowledge and history of life in the rural area of Marabá-PA
}

\begin{abstract}
The article presents results of a socio-educational Research Internship Teaching II, with emphasis on Mathematics held at Ipê flower community. The aim is to discuss practices with Financial Mathematics from subjects of narratives field. It is based on the stories of life and work of livestock activity of two producers of the said community milks. The results indicate that the appreciation of mathematical knowledge derived from social field practices contributes to the strengthening of some political principles, teaching and learning in school education field. Beyond the contextualized training, the reality and experiences of the camp communities as an object of study and source of knowledge.
\end{abstract}

Keywords: Rural Education, Narratives, Practices with Mathematics. 


\section{El conocimiento matemático y la historia de la vida en el area rural de Marabá - PA}

RESUMEN. El artículo presenta los resultados de un socioeducativa Investigación Práctica de Docencia II, con énfasis en Matemáticas, celebrada en comunidad flor de Ipê. El objetivo es discutir con las prácticas matemáticas financieras de los sujetos del campo narrativas. Se básenlas historias de vida y de trabajo de la actividad ganadera de dos productores de dichas leches comunidad. Los resultados indican que la apreciación del conocimiento matemático derivado de prácticas de campo social es contribuye al fortalecimiento de algunos principios políticos, la enseñanza y el aprendizaje en el campo de la educación escolar. Además de la formación contextualizada, la realidad y las experiencias de las comunidades de los campos como un objeto de estudio y fuente de conocimiento.

Palabras-clave: Educación Rural, Narrativas, Prácticas con las Matemáticas. 


\section{Introdução}

A Educação do Campo é uma área de conhecimento que está associada à possibilidade de implementações de proposições instituídas de princípios políticos, pedagógicos e didáticos sobre o saber inerente as áreas de conhecimentos. Prima por uma educação voltada à realidade dos sujeitos do campo e a formação de professores-educadores aptos para atuarem nessas escolas, além da formação docente, habilitar o docente a trabalhar os conteúdos e construir currículos que atendam as demandas pedagógicas do Ensino Fundamental e Ensino Médio.

$\mathrm{O}$ curso de Licenciatura em Educação do Campo é um ponto de chegada a essas perspectivas ao ser implementada em várias Universidades do Brasil. Aponta para a relevância da realização de atividades acadêmicas como catalisadora do processo de ensino e aprendizagem na coligação dialógica entre ensino, pesquisa e extensão para além do espaço da universidade. E admite princípios pedagógicos curriculares como: a formação contextualizada, a interdisciplinaridade, a realidade $\mathrm{e}$ as experiências das comunidades do campo como objeto de estudo e fonte de conhecimento (PPC/Fecampo, 2014).
Prevê no perfil do egresso do curso uma formação em que seja capaz de "ter atuação pedagógica nas comunidades rurais, para além da prática escolar" (PPC/Fecampo, 2014, p 19). Essa atuação, para além das práticas escolares, requer ações que dê condições pedagógicas para uma organização curricular através de núcleos de estudo, que contemplem e articulem eixos de formação com fulcro em saberes matemáticos, que os sujeitos possam vivenciar nas práticas socioculturais campesinas, a partir das narrativas de suas histórias de vidas, por exemplo.

Este trabalho surge de uma pesquisa embasada nas narrativas de produtores de leite bovino da comunidade Flor do Ipê. Visa contribuir na visibilidade pedagógica e didática de saberes matemáticos escolar e extraescolar, a partir de Práticas com Matemáticas observadas nessas narrativas. Traz em seu bojo a possibilidade de compreensão sobre alguns conhecimentos de Matemática Financeira. Vincula-se a princípios políticos e pedagógicos da Educação do Campo como fatores que podem suscitar o desencadeamento de descortinações de Práticas com Matemáticas no cotidiano dos sujeitos da comunidade e no processo de formação docente para o campo. 
Ao analisar as histórias de vida e trabalhos de um produtor percebemos a importância de saberes matemáticos no processo de produção de leite. As narrativas do produtor permitiu refletirmos sobre diferentes objetos matemáticos, imprescindível para realizar atividades e situações de ensino escolar.

\section{Aspectos da Educação Matemática e da Educação do Campo}

Algumas concepções teóricas da Educação Matemática permite refletir sobre práticas socioculturais no contexto da Educação do Campo. A Etnomatemática é uma tendência de educação matemática fundamental para analisar contextos socioculturais onde $\mathrm{o}$ saber está de certo modo implícito nas práticas sociais dos sujeitos.

A Etnomatemática abre leques que possibilita o processo de contextualização incidir em dois fatores cruciais: $a$ visibilidade de apreender matemática a partir das produções existentes na comunidade; esse elemento coloca em cheque as relações das famílias com o que se produz e através dessas relações oferecerem condição de essas produções serem objetos de estudo na comunidade e condiciona construção de conhecimento para a classe estudantil: identidade cultural de grupos sociais; a partir da proximidade e pesquisas realizadas, além de ter esse fator importante de ensino, contribui, de certa forma, para a valorização de identidades a partir da formação de sujeitos críticos e emancipados. Ao evidenciar e trabalhar de forma prática, esse estudo resgata costumes e valores culturais inseridos nas produções das etnocomunidades.

De acordo com D'Ambrosio (2001), a Etnomatemática não é apenas o estudo de "matemáticas das diversas etnias", mas sim, é o estudo das diferentes maneiras, artes, estilo, técnicas de explicar, aprender, conhecer e lidar com o ambiente social, cultural e até mesmo imaginário das e nas diferentes culturas e ou sociedades. A Etnomatemática é uma prática espontânea e natural na busca pela sobrevivência e estimula a criatividade e a descoberta.

Em D’Ambrosio (2002), a Etnomatemática é um programa de pesquisa em história e filosofia da Matemática, com consideráveis implicações pedagógicas. Tem sua origem na busca de entender o fazer e o saber matemático e se expande a partir da dinâmica da evolução de fazeres e saberes que resultam da exposição mútua de culturas. Além da importante visão de D’Ambrosio (idem), outro autor pósestruturalista promove uma discussão que faz o intercâmbio entre as ideias do autor 
mencionado acima, ajudando e esclarecendo que, a perspectiva da Etnomatemática é de o sujeito se perceber no ambiente ao qual está inserido, vivendo no mundo e entendendo-o como sujeito principal estando nele.

Para Bampi (2003), trabalhar a Etnomatemática em sala de aula implica em trabalhar com modelagem matemática concomitantemente, pois só assim serão alcançados os objetivos educacionais em grupos de estudo. Dessa forma, a Etnomatemática pode contribuir para o desenvolvimento do pensamento e a aquisição de atitudes, visando construir no aprendiz a capacidade de resolver problemas, gerando hábitos de investigação, proporcionando confiança e desprendimento para analisar e enfrentar situações novas. Nesse sentido, ela auxilia no desenvolvimento de outras capacidades pessoais, por exemplo, um adolescente, através da matemática financeira, pode aprender administrar a próxima mesada para que o seu dinheiro dure em torno no decorrer de um mês. A partir dessa esteira, entendermos que as pessoas são partes das realidades e que pode modifica-la e, é a partir de uma abordagem Etnomatemática valorizando a realidade do aluno que conseguimos a contextualização, o sociocultural dos conteúdos acadêmicos.
Portanto, a Etnomatemática focaliza na geração, organização e difusão de conhecimento. Estando entre suas preocupações o estudo da cognição, da epistemologia, da história e da sociologia. Por outro lado, seu conceito abrange grupos culturais identificáveis. Sua memória, sua organização, seus códigos e símbolos, suas práticas sociais (Ferreira, 1991). Esses grupos reúnem e mobilizam maneiras de como fazer, executar as tarefas rotineiras ao usar ferramentas matemáticas autotecnológicas para resolver situações do cotidiano escolar, extraescolar das Etnocomunidades (Gaia \& Guerra, 2014).

As Etnocomunidades são caracterizadas por Gaia e Guerra (2014) como instituições socioculturais que em suas atividades humanas desenvolvem e organizam práticas sociais visando atender as suas necessidades específicas e/ou coletivas. Incluem diversas realidades socioculturais, tais como comunidades que estão nos espaços urbanos e ou rurais, entre os quais: grupos de trabalhadores, indígenas, ribeirinhos, quilombolas, assentados e outros grupos identificados como movimentos sociais, que em suas práticas sociais tem uma história lembrada por alguma razão institucional e um modo particular de movimentar objetos culturais, inclusive saberes e fazeres, valores, 
crenças, costumes e gestos nas suas práticas socioculturais. Dentre as práticas desenvolvidas pela Etnocomunidades, admitimos as práticas sociais com matemáticas ou práticas com matemáticas como o desenvolvimento de técnicas com objetos matemáticos nas situações laborais dos sujeitos.

Segundo Gaia e Guerra (2014), as práticas sociais com matemáticas são entendidas como atividades humanas realizadas nos contextos das Etnocomunidades, aprovisionada pela técnica com objetos matemáticos, usada na resolução de tarefas/situações problemas. Cujas manifestações podem ser evidenciadas nos discursos verbais, escritos e ou gestuais, isto é, com alguma característica sociocomunicativa.

Chevallard admite que o desenvolvimento da técnica esteja no coração da atividade matemática (Chevallard, 1999). As práticas com matemáticas mobilizam técnicas com objetos matemáticos, ativam processos de raciocínio intuitivos e tecnológicos que incluem costumes, valores, poderes, ações e práticas comuns como elementos caracterizadores da identidade das Etnocomunidades (Gaia \& Guerra, 2014). Assim, descobrir a técnica utilizada pelos sujeitos é também evidenciar a sua relação com o saber matemático e obter uma oportunidade de elaborar cartografias dos processos e técnicas utilizados.

Essa atitude pode manifestar parte da constituição do protagonismo dos sujeitos do campo brasileiro, suas organizações sociais, suas historias de vidas; fundamentais para reconhecimento e validação das atividades que se realizam no âmbito das Etnocomunidades. Esse protagonismo implica pensar em práticas docentes da Educação do Campo de maneira distinta da lógica urbanocêntrica. Rocha e Martins asseguram que

é necessário pensarmos nossas práticas educacionais, inclusive as que se referem ao conhecimento matemático, a partir de uma outra lógica diferenciada da lógica urbanocêntrica, quer seja a lógica da terra, a lógica do campo e, sobretudo, a dos sujeitos que ali vivem, constroem e defendem seu modus vivendi (Rocha \& Martins, 2009, p. $1)$.

Nesse aspecto o protagonismo dos sujeitos do campo coloca as dimensões socioculturais, políticas, econômicas, sociológicas e pedagógicas como elementos fundamentais para complementação e potencialização do saber escolar. Mas, é bom lembrar que os discentes trazem suas vivências, suas historias de vida, saberes, valores, identidades, seus processos de raciocínio e estratégia de resolução de problemas 
matemáticos para as escolas, adquiridas em suas experiências cotidianas; mas, o que a escola faz com esses saberes e valores? As respostas a indagações como essa não são muito simples, são complexas do ponto de vista socioeducativo.

$$
\text { Portanto, o conhecimento }
$$
matemático do currículo das escolas do campo/rurais parece não atender as demandas socioculturais dos sujeitos e nem acolhe suas experiências. Logo, valorizar essa dimensão pode respaldar o trabalho pedagógico docente, como elementos potencializadores na construção do conhecimento matemático pelos alunos do campo.

Mas, essas questões abrem caminhos ao trato de concepções que possam potencializar transformações sobre o olhar epistêmico, político e pedagógico das práticas docentes do campo, no âmbito da valorização e visibilidade de objetos de saberes matemáticos de grupos socioculturais. Gradativamente acolher novas concepções de ensino pautado na realidade local com propostas desencadeadoras em atendimento às especificidades dos sujeitos da localidade. Essa demanda tem como princípio fundamental, a realização de pesquisas socioeducativa embasadas nas diversas formas de produção, organização espaçotempo dos sujeitos do campo.

\section{Narrativas como Abordagem de Pesquisa nas Práticas Sociais do Campo}

A narrativa é uma abordagem teórico-metodológica importante para compreender interações sociais nas práticas sociais dos sujeitos das Etnocomunidades. Desenvolvida por Harvey Sacks (1984) e aprimorado por Garcez (2001), as narrativas são possibilidades de construtos obtidos a partir de conversações cotidianas contadas/narradas informalmente em entrevistas de pesquisas.

As narrativas podem surgir como respostas tanto a perguntas abertas quanto a perguntas fechadas. Mishler (2002), além de ressaltar que as narrativas podem ser principiadas por perguntas diretas para se contar uma história, analisa a dinamicidade do processo de construção identitária. Se por um lado, podem aparecer como respostas a perguntas específicas sobre eventos e experiências de vida, por outro também é uma possibilidade de observar na história de vida e trabalho de sujeitos, objetos de ensino escolar e extraescolar das mais diversas áreas de conhecimentos da educação.

Para Megid e Fiorentini (2011), há um duplo papel exercido pela narrativa no contexto da formação docente. $\mathrm{O}$ primeiro concebe a narrativa como uma 
possibilidade de refletir, relatar e representar a experiência, produzindo sentido ao que somos, fazemos, pensamos, sentimos e dizemos. O segundo refere-se na maneira como estudar e investigar a experiência; podendo ser realizada interpretações na compreensão da experiência humana, sem descartar a perspectiva e interpretação de seus participantes.

Neste trabalho usamos as narrativas para buscarmos indícios de práticas com matemáticas relativas às produções de leite bovino pelo senhor Manoel Messias ao longo de sua trajetória de vida e trabalho. Tendo sido feita a coleta de dados por meio das narrativas orais com os sujeitos, organizamos sistemas de tarefas que podem ser usados no ensino escolar por docentes de escolas do campo.

A essas organizações atrelamos a ocorrência de contribuições para o formador de professores advindas dessas práticas, lições que a experiência pode trazer para a formação inicial de professores do ensino básico. Assim, podemos destacar as potencialidades da abordagem das narrativas em processos de conversação informal, com auxílio de questões abertas.

Esta pesquisa teve origem a partir do Estágio de Docência, atividades curriculares obrigatórias do Curso de
Licenciatura em Educação do Campo, do Instituto de Ciências Humanas da Universidade Federal do Sul e Sudeste do Pará. Vinculada ao projeto PAPIM intitulado "Práticas socioculturais com Matemáticas e Gêneros textuais: ensino interdisciplinar para escolas multisseriadas da zona rural de Marabá$P A$ ”, do Programa de Apoio a Projetos de Intervenção Metodológica (PAPIM) da Pró-Reitoria de Ensino de Graduação da Universidade Federal do Sul e Sudeste do Pará (PROEG-UINIFESSPA) e executado na Faculdade de Educação do Campo (FECAMPO) do Instituto de Ciência da Educação (ICH) /UNIFESSPA.

A pesquisa Socioeducacional foi realizada na comunidade Flor do Ipê. No decorrer da pesquisa percebemos condições para a valorização de saberes matemáticos utilizados pelos sujeitos e suas atividades laborais.

Para, além disso, podemos inferir que as práticas sociais do campo admitem princípios pedagógicos curriculares como: a formação contextualizada, a realidade $e$ as experiências das comunidades do campo como objeto de estudo e fonte de conhecimento (PPC/Fecampo, 2014). Assim, contribui para a o fortalecimento da perspectiva da formação docente do educador do campo, com fulcro nas vivências campesinas. 
A realidade e as experiências das comunidades do campo como objeto de estudo e fonte de conhecimentos são elementos essenciais para que: discentes do curso da Educação do Campo possam vivenciar essa possibilidade de reconstrução do saber atuando como professor-pesquisador em formação; os sujeitos das comunidades locais sejam atores sociais no ponto de partida de saberes acumulados e utilizados nesse contexto; e as experiências dessas Etnocomunidades, aqui entendidas como grupos socioculturais organizados para atender suas necessidades comuns, fonte de saberes imprescindível para a sua sobrevivência.

A formação contextualizada é um princípio educativo fundamental a ser alcançado, pois com esse se pretende identificar sabres matemáticos presentes nas práticas socioculturais dos sujeitos do campo. A contextualização é uma organização cujos elementos pedagógicos não são estranhos para os sujeitos; é um espaço de seu domínio de conhecimento empírico que pode ser valorizado e potencializado para o âmbito escolar ou acadêmico/cientifico.

A prática da pesquisa pressupõe a oportunidade dos discentes, do curso de Licenciatura em Educação do Campo, relacionarem-se com os saberes que vivem nas práticas sociais que passam despercebidos de seus olhares, como saber que pode estar no ambiente de formação escolar; é a oportunidade dos discentes colocarem em prática a possibilidade de descortinar e reconhecer no tempo comunidade, conhecimentos vivenciados no tempo universidade e assim produzindo e organizando novos conhecimentos a partir da relação campo e universidade.

\section{Saberes matemáticos nas narrativas}

As narrativas de produtores de leite bovino da comunidade Flor do Ipê embasam questões relativas à produção de leite, criação e comércio de animais (gado e suíno), deixa clara a presença de assuntos diversos de matemática. Propomos uma lista de situações envolvendo objeto de saber matemático (práticas com matemáticas), percebidos nas narrativas de um dos produtores da comunidade. Certamente pode haver objetos e saberes matemáticos nas narrativas que não estão nas situações-problemas, deixando assim um espaço para o exercício docente em observar e propor outras situações e tarefas de ensino.

\section{Narrativas do Sr. Manoel Messias}

O Sr. Manoel Messias (ou doravante chamado de seu Manoel) é um produtor de 
leite que contribui muito para o abastecimento no laticínio do Edmar Paulo desde 2014. Ele iniciou com a produção de leite desde 1995. Segundo seu Manoel é por meio dessa produção consegue sua sobrevivência de toda a família. Do lucro do leite ele investe em sua pequena propriedade rural, tais como pastagem, reforma de cerca, e também com medicamentos em seus animais. "Com o passar do tempo essa produção aumentou bastante", afirma seu Manoel. "Hoje retiro em média 100 litros de leite diário. O leite hoje na região é muito barato, o litro custar $\mathrm{R} \$ 0,50$ centavos. Mesmo sendo tão barato ainda dá para suprir algumas necessidades, consigo pagar as mensalidades que gasto com as vacas. Só com sal esse gasto mensal é de $\mathrm{R} \$ 120,00$ com sal e mineral, gasto também com vacina de 6 em 6 meses”, explica seu Manoel. Mesmo com o valor do leite barato na região seu Manoel consegue um valor bruto mensal em média de $\mathrm{R} \$ 2000,00$. Ao pagar todas as despesas ele ainda salda R\$ 1000,00. Seu Manoel faz questão de destacar que com esse valor liquido não faz nenhum depósito em banco, investe tudo em gado. Seu Manoel vende massa de cuim, e dela é retirado o soro. No entanto, seu Manoel esclarece que "de 65 litros de leite, depois da massa pronta, é possível retirar 60 litros de soro. Com 60 litros de soro e com a compra de 7 sacas de cuim, pode-se criar 8 suínos repercutindo esse processo durante 7 meses. Em sete meses os suínos pesarão em média $40 \mathrm{~kg}$ cada". Seu Manoel fala sem desanimar que já fez um empréstimo no valor de $\mathrm{R} \$ 50.000,00$. Com três anos de carência para investir na terra e comprar mais gados, "mesmo sabendo que depois dos três anos de carência o banco cobra uma taxa de juros de $2 \%$, não desanimei, só que trabalhando direitinho consegui tirar um lucrozinho", seu Manoel conclui, mas não revela de quanto foi o lucro. Dá para perceber que seu Manoel gosta muito de exercer essa atividade, por isso ele investe tanto na venda do leite, quanto na compra do gado.

\section{Regra de Três, Proporção e Redução à Unidade das Narrativas de seu Manoel}

1) Com base na venda de leite, seu Manoel obtém R \$2000,00 bruto, sem descontar as despesas. Considerando que o litro do leite é R\$ 0,50. Quantos litros de leite seu Manoel deve extrair de sua produção para obter esse montante de R $\$ 2000,00$ ?

A solução pode ser dada de três maneiras:

1.1) Solução por Regra de Três direta:

$\begin{array}{lll}\text { Litro } & \mathrm{R} \$ & 0,50 \mathrm{x}=2000 \\ 1 & 0,50 & \mathrm{x}=4000 \text { litros } \\ \mathrm{X} & 2000 & \end{array}$


1.2) Solução por Proporção:

$\frac{1 \text { litro }}{R S 0,50}=\frac{x \text { litros }}{2000 \mathrm{RS}} \quad 2=\frac{x \text { litros }}{2000} \mathrm{X}=2 * 2000$ $\mathrm{x}=4000$ litros

\section{3) Solução por Redução à Unidade}

Resolver essa tarefa por redução à unidade (método de redução à unidade) seria o mais simples, pelo fato de que na redução à unidade se procura "quanto de um corresponde a uma unidade do outro" e nesse caso, temos que ter uma taxa unitária que é $\frac{1}{0,50}=2$; logo devemos multiplicar essa taxa pela quantidade que se procura, isto é: $2 * 2000=4000$ litros de leite.

Observe-se que na redução à unidade não se leva em conta as grandezas que são de espécies diferentes. Aliás, esse é um obstáculo epistemológico em que para os matemáticos essa é uma prática que não estaria de acordo com a normatização da cultura matemática científica por infringir o rigor da matemática, no entanto, a redução à unidade está quase que em todos os cálculos que envolvem razões, mesmo de espécie diferentes, nas Ciências Aplicadas; por exemplo: cálculo de velocidade (Física); Densidade Populacional (Geografia); Cálculo do IMC (Educação Física); Densidade de uma solução (Química) etc. Gaia (2016) em sua Tese de Doutorado aborda sobre a ecologia do Método de Redução à Unidade, onde o define como um objeto matemático escolar que emerge nas práticas sociais com matemáticas de comércio e de ofícios diversos. É uma técnica primária, elementar por sua simplicidade didática e uso nas atividades cotidianas.

\section{Taxas, Porcentagens e Juros nas Narrativas de seu Manoel}

Manoel é um produtor muito conhecido na Vila Flor do Ipê, segundo ele, desde 1995 seu meio de produção sempre foi o leite. Ele gosta muito de exercer essa profissão, mas para esse meio de produtividade gerar renda e lucro tem que gastar bastante, principalmente no roço de mangas, cercas, ração para as vacas, dentre outros. Com isso, seu Manoel contraiu um empréstimo bancário de $\mathrm{R} \$$ 50.000,00 a começar a pagar depois de três anos de carência. Depois dos três anos, ele pagou a primeira parcela no valor de $\mathrm{R} \$$ $10.000,00$ depois da primeira parcela paga e, mesmo não atrasando as demais parcelas ele disse que o banco passou a cobrar uma taxa de $2 \%$ anual. Com base no texto da narrativa, sugerimos um sistema de tarefas que podem ser aplicadas no ensino básico. A tarefa 1 foi resolvida pelo pesquisado. A tarefa 2 foi solucionada pelo entrevistado. As demais foram problematizadas e solucionadas pelo pesquisador. 
1) Qual o valor em reais da taxa de $2 \%$ cobrada pelo banco ao seu Manoel?

$$
2 \%=\frac{2}{100}=0,02 R \$
$$

2) Quando indagamos ao seu Manoel Messias sobre a forma de pagamento do referido empréstimo no valor de $\mathrm{R} \$ 50$ 000. Considerando que ele deveria pagar a primeira parcela no valor de $\mathrm{R} \$ 10000$, sabendo que cada ano a taxa é de $2 \%$ no Sistema de Juro compostos, então perguntamos: quanto ficaria o valor final de sua dívida depois?

$$
R \$ 50000+R \$ 2000=R \$ 52000
$$

Segundo seu Manoel Messias a sua divida seria de $\mathrm{R} \$ 52000$

(Solução dada pelo entrevistado)

Mas, os resultados calculados pelos sistemas de juros simples ou compostos da teoria da matemática financeira nos mostra o seguinte, tarefas 2 e 3 :

3) Quanto seu Manoel pagará, no sistema de juros simples,ao banco, à taxa de $2 \%$ ao ano sobre o montante emprestado?

Resolução: $\quad$ sendo $J=\frac{c \cdot i \cdot t}{100}$ a fórmula do cálculo de juros simples, temos que:

$J=\frac{50000.2 .1}{100}=1.000,00$

Portanto, seu Manoel pagará Um Mil reais de juros ao banco neste ano.
4) Quanto seu Manoel pagará, no sistema de juros compostos, ao banco, à taxa de $2 \%$ ao ano sobre o montante emprestado?

Resolução: Primeiro devemos calcular o montante $M$, onde o Capital $C$, à taxa $i$, aplicados a $\boldsymbol{t}$ tempo. Temos: $M=C *(1$ $+i)^{t}$ a fórmula do cálculo de juros compostos, substituindo:

$M=50.000 *(1+0,02)^{1}$

$M=50.000 *(1,02)^{1}$

$M=50.000 * 1,02$

$M=51.000 R \$$

No entanto: o Montante $M$ é o Capital mais os Juros, isto é, $M=C+J$

Logo, os Juros aplicados pelo banco que deverá ser pago por seu Manoel será de J $=M-C$,

$$
J=51.000-50.000=1.000
$$

Devemos observar que aparentemente não há diferença entre os resultados obtidos no cálculo de juros simples e juros compostos, no entanto, quando o tempo é Maior que 1, esses resultados será distintos, o resultado no sistema de juros compostos $>$ que o resultado no sistema de juros simples.

5) Ao final de 6 anos seu Manoel havia amortizado seu empréstimo. Ele foi ao banco e emitiu o extrato de sua conta, sabendo que a taxa aplica foi de $2 \%$ ao ano no Sistema de Juros Compostos:

a) Quanto seu Manoel Messias pagou de juros compostos ao final de 6 anos? 
Resolução: Primeiro devemos calcular o montante $M$, onde o Capital $C$, à taxa $i$, aplicados a $t$ tempo. Temos: $M=C *(1$ $+i)^{t} a$ fórmula do cálculo de juros compostos, substituindo:

$M=50.000 *(1+0,02)^{6}$

$M=50.000 *(1,02)^{6}$

$M=50.000 * 1,126$

$M=56.300 R \$$

No entanto: o Montante $M$ é o Capital mais os Juros, isto é, $M=C+J$

Logo, os Juros aplicados pelo banco que deverá ser pago por seu Manoel será de J $=M-C$,

$J=56.300-50.000=6.300$

Obs.: Seu Manoel pagou 300,00 a mais neste sistema de juros em relação aos juros simples.

b) Se fosse ao sistema de juros simples quanto seu Manoel pagaria de juros?

Resolução: $\quad$ sendo $J=\frac{c \cdot i \cdot t}{100}$ a fórmula do cálculo de juros simples, temos que:

$J=\frac{50000.2 .6}{100}=6.000,00$ Portanto, seu Manoel pagaria apenas Seis Mil reais de juros ao banco; $R \$ 300,00$ a menos que no sistema de juros compostos.

Nota-se a importância de conhecer os fundamentos de matemática financeira, onde se pode adotar uma postura crítica e consciente no seu papel de cliente bancário ou consumidor diante de situações para resolução de problemas de ordem financeira, como cálculo do valor de prestações, pagamentos de impostos, rendimento de poupanças, pagamentos de juros em empréstimos e outras. Não há um entendimento das pessoas sobre as taxas de juros aplicadas pelas lojas e instituições bancárias, mas essas relações matemáticas estão no cotidiano das pessoas, embora a falta de contextualização como algo significativo e não fictício para os discentes pairam nas práticas com matemáticas escolares.

Deve-se deixar clara a diferença entre os juros aplicados no sistema simples e compostos. Certamente as instituições bancárias realizam empréstimos ao consumidor a juros compostos, mas aplicam às cadernetas de poupanças taxas a juros simples. Uma diferença exponencial que deixa as instituições bancárias em vantagens exorbitantes nessa relação financeira. Uma análise didáticopedagógica dessas diferenças, não pode omitir a informação de como o sistema financeiro se alimenta dessa relação desigual e, às vezes, desonestas, desleais, ferozes com o cidadão.

Refletindo sobre as práticas com Matemáticas nas narrativas do Produtor 
Podemos considerar que os textos narrativos orais ofereceram subsídios para elaborações, construções e resoluções de situações-problema, na perspectiva de se trabalhar a realidade do campo de forma contextualizada, uma possibilidade para que o conhecimento matemático seja trabalhado na escola do campo.

Inferimos que o conhecimento empírico do produtor foi exposto a partir de suas narrativas orais das histórias de vida e trabalho. E neste relato está sua identidade cultural e habilidades e fragilidades em se relacionar com o conhecimento matemático. Este é uma ferramenta de aplicação nas práticas sociais, no ensino e aprendizagem escolar. Saberes que podem ser valorizados em sala de aula como ponto de partida do local para o universal.

Os sistemas de tarefas de ensino de Matemática baseado na realidade de vida do campo colocam a oportunidade da escola tratar de temas envolvendo práticas com matemáticas importantes para a vida e trabalho dos sujeitos da zona rural. A escola não pode se esquivar dessa condição de esclarecedora do exercício da cidadania financeira para não outorgar o papel de escudeira da elite financeira do país.

A escola precisa tocar e discutir os problemas comunitários propondo alternativas e esclarecimentos sobre economia, política, trabalho e outros temas que possam alargar o conhecimento discente do local para o universal. Assim, os alunos terão a oportunidade vivenciar conhecimentos escolares e do cotidiano envolvendo conceitos e procedimentos matemáticos podendo ampliar a visão que tem dos problemas socioculturais que o cercam.

De acordo com Moura (2005), a escola nem toca em assuntos da comunidade que devem ser discutidos. É hora de identificar os conhecimentos que os familiares possuem sobre vida $\mathrm{e}$ trabalho e se quiser fazê-lo precisa interagir com os conhecimentos locais que não estão sistematizados nos livros didáticos e nem acabados, precisam ser construídos. Porque os conhecimentos repassados na faculdade não trata o lugar onde a escola se encontra ou onde as pessoas vivem; não ilumina os problemas reais, nem inspira solução, não descobre as potencialidades.

As especificidades das tarefas de ensino dialogam com a realidade da vida cotidiana do sujeito. A resolução de tais atividades quando desenvolvidas podem ser atribuídas a um método de ensino escolar, desde que sejam atividades pertinentes ao que se pretende. A resolução de problemas indicados pelos educadores matemáticos deve possibilitar aos alunos 
conhecimentos e desenvolver a capacidade para gerenciar as informações que estão ao seu alcance (Brasil, 1998).

Gaia e Guerra (2014) afirma que a educação do campo vem sendo um paradigma de educação básica de qualidade para os espaços não urbanos. Surge para a superação de ruptura do modelo de educação rural ainda vigente. Essa ruptura também se dá no sentido de novas proposições de organizações didáticas e matemáticas para o ensino dessa área de conhecimento para o campo.

O profissional da educação do campo deve assumir em sua tarefa docente saberes construídos e utilizados pelas populações do campo, indispensáveis para a aprendizagem dos discentes desse contexto. Com isso, cada atividade com matemática poderá concretizar a aprendizagens necessárias na resolução de problemas que fazem parte de sua vida. Estudar a realidade circundante é buscar entendimento do que está acontecendo nesse espaço sem diminuir o conteúdo escolar, seja na comunidade onde esses sujeitos estão inseridos, seja em universo mais global.

Tudo que existe num lugar está em relação com os outros elementos desse lugar. O que define o lugar é exatamente uma teia de objetos e ações com causa e efeito, que forma um contexto $\mathrm{e}$ atinge todas as variáveis já existentes, internas; e as novas, que se vão internalizar (Santos, 1994, p. 97).

Esse entendimento gera necessariamente um processo de relações sobre o que existe e porque existe. Nessa perspectiva a escola não pode ser simplesmente uma instituição que cumpre os conteúdos curriculares impostos pelo sistema, ela deve desenvolver atividades as quais tornam o sujeito capaz de perceber os mecanismos de sujeições institucionais que interferem em seu modo de ser e pensar. Mecanismo esse movido com o objeto de saber que carrega um amplo significado, o de manter atitudes ou de mudar procedimentos do sujeito diante do seu papel de cidadão crítico. Santos afirma que estamos vivendo num mundo que precisa ser conhecido e compreendido, não pelo lugar em si, mas pelo conjunto no qual ele se contextualize (Santos, 2003).

Os sujeitos precisam discernir agentes de sistematização de sujeições o porquê das coisas e como as são? E quais são? Tal indagação poderá ser instigada na relação dialética entre professor e educando no contexto do saber escolar e extraescolar. A escola precisa aguçar a capacidade do educando para promover a construção de seu conhecimento crítico em relação com o cotidiano, que forma sua identidade cultural, social e o seu pertencimento. Segundo Santos (2003), o 
sentimento de pertencimento a um determinado lugar constrói uma introspecção de valores.

Rocha e Martins (2009) argumentam que é necessário pensarmos nossas práticas educacionais, a partir de outra lógica, "que seja a lógica da terra, a lógica do campo e, sobretudo, a dos sujeitos que ali vivem, constroem e defendem seus modos de vida" (Rocha \& Martins, 2009). Nessa perspectiva as práticas com matemáticas não podem ser desvinculados modos próprios de pensar matematicamente o mundo experienciado pelo homem/mulher, no e do campo em suas práticas sociais. Isso significa dizer que devemos incorporar em nossas práticas educacionais atividades articuladas com forma de vida, trabalho, cultura dos sujeitos da comunidade em que a nossa escola está inserida.

\section{Considerações finais}

Os objetos Matemáticos são ferramentas científicas essenciais para solucionar atividades humanas. A matemática escolar contextualizada mostra-se como recurso efetivo para problemas aplicados. Estudar a realidade dos sujeitos e compreendê-la do ponto de vista da Educação Matemática não é a escola simplesmente cumprindo conteúdos curriculares, mas desenvolvendo atividades que o sujeito seja capaz de conhecer e interagir socioculturalmente.

Além da formação contextualizada, a realidade e as experiências das comunidades do campo como podem ser incluída objeto de estudo e fonte de conhecimento em articulação com saberes escolares. Pode, pois, fornecer elementos pedagógicos e didáticos de forma reflexiva e prática como condições para repensar o ensino de Matemática de escolas do campo tendo como ponto de partida a história de vida e o trabalho laboral de pessoas da própria comunidade local, numa perspectiva das práticas com matemáticas.

Este pensar implica caminhar na direção de novas perspectivas para a educação do campo no sentido de pesquisar e elaborar propostas didáticopedagógicas qual atendam as necessidades cotidianas dos sujeitos. Uma das principais ações a se problematizar é transformar o aspecto local em conteúdo a serem trabalhados nas mais diversas comunidades. Essa ação contribuirá em desconstruir o modelo tradicional que as escolas têm adotado. Concluímos que a valorização de saberes matemáticos oriundos das práticas sociais do campo contribui para a o fortalecimento de alguns princípios políticos, pedagógicos e didáticos do ensino escolar do campo. 
Acreditamos ter alcançado os objetivos propostos nesse trabalho. Discutir e apresentar práticas com Matemáticas a partir de narrativas de sujeitos do campo, tendo como base as histórias de vida e trabalho da atividade pecuária de um pequeno produtor de leite da referida comunidade. Não podemos deixar de mencionar que em um segundo momento, na continuidade da atividade de Estágio Acadêmico do curso de Licenciatura em Educação do Campo, na comunidade Flor do Ipê, implementamos os sistemas de tarefas aqui apresentados em uma escola da comunidade; cujos relatos e análises deixamos para um próximo trabalho.

\section{Referências}

Bampi, L. R. (2003). Governo etnomatemático: tecnologias do multiculturalismo. (Tese de Doutorado). Universidade Federal do Rio Grande do Sul, Porto Alegre.

Brasil. (1998). Parâmetros Curriculares Nacionais (PCN): Matemática. Secretaria de Educação Fundamental - Brasília: $\mathrm{MEC} / \mathrm{SEF}$.

Chevallard, Y. (1999). El análisis de las prácticas docentes en la teoría antropológica de lo didáctico. Recherchesen Didactique des Mathématiques, 19(2), 221-266.

D'Ambrosio, U. (2001). Educação pra uma sociedade em transição. Campinas, SP: Papirus.
D'Ambrosio, U. (2002). Etnomatemática: elo entre as tradições e a modernidade. Belo Horizonte: Autêntica.

Fecampo/Unifesspa. (2014). Projeto Pedagógico do Curso de Licenciatura em Educação do Campo. Marabá-PA: ICH.

Ferreira, S. (1991). Por uma teoria de Etnomatemática. Bolema, 7.

Gaia, C. A., \& Guerra, R. (2014). Descortinando Práticas com Matemáticas: Conexões entre TAD e Etnomatemática; In Mendes, I., \& Farias, C. A. Práticas socioculturais e Educação Matemática. São Paulo: Livraria da Física.

Garcez, P. (2001). Deixa eu te contar uma coisa: o trabalho sociológico do narrar na conversa cotidiana. In Ribeiro, B. T., Lima, C. C., \& Dantas, M. T. (Orgs.). Narrativa, identidade e clínica. Rio de Janeiro: Ipub.

Megid, M. A. B. A., \& Fiorentini, D. (2011). As Narrativas e o Processo de Aprendizagem Docente. Revista Interações, 18, 178 -203.

Mishler. (2002). Narrativa e identidade: a mão dupla do tempo. In Lopes, L. P., \& Bastos, L. C. (Orgs.). Identidades: recortes multi e interdisciplinares. Campinas: Mercado de Letras.

Antunes-Rocha, M. I., \& Martins, A. A. (2009). Formar docentes para a educação do campo: Desafios para os movimentos sociais e para a Universidade. In Rocha, M. I. A., \& Martins, A. A. (Orgs.) Educação do campo: desafios para a formação de professores. Belo Horizonte: Autêntica.

Moura, A. (2005). Filosofia e Princípios de PEADS (PE) e do CAT (BA). In Baptista, F. M., \& Batista, N. Q. Educação Rural 
Sustentabilidade do Campo. Feira de Santana, BA: SERTA.

Sacks, H. (1984). On doing "being ordinary". In J. Atkinson, M., \& Heritage, J. (Orgs.). Structures of social action: studies in conversation analysis. Cambridge: University Press.

Santos, M. (1994). Metamorfoses do espaço habitado. São Paulo: Hucitec.

Santos, M. (2003). A natureza do espaço: técnica, tempo, razão e emoção. São Paulo: Edusp.

Recebido em: 06/06/2016 Aprovado em: 20/07/2016 Publicado em: 03/08/2016

Como citar este artigo / How to cite this article / Como citar este artículo:

APA:

Gaia, C., \& Pires, L. S. (2016). Saberes matemáticos e história de vida na zona rural de Marabá-PA. Rev. Bras. Educ. Camp., 1(1), 128-146.

ABNT:

GAIA, C.; PIRES, L. S. Saberes matemáticos e história de vida na zona rural de Marabá-PA. Rev. Bras. Educ. Camp., Tocantinópolis, v. 1, n. 1, p. 128-146, 2016. 